\title{
Spontaneous reperfusion before intervention improves immediate but not long-term prognosis in diabetic patients with ST-segment elevation myocardial infarction and multivessel coronary artery disease
}

\author{
Andrzej Lekston ${ }^{1}$, Bartosz Hudzik ${ }^{1}$, Janusz Szkodziński ${ }^{1}$, Mariusz Gąsior ${ }^{1}$, \\ Mateusz Tajstra ${ }^{1}$, Zbigniew Kalarus ${ }^{2}$, Bożena Szyguła-Jurkiewicz ${ }^{1}$, Lech Poloński ${ }^{1}$ \\ ${ }^{1} 3^{\text {rd }}$ Department of Cardiology, Silesian Center for Heart Disease, \\ Medical University of Silesia, Zabrze, Poland \\ ${ }^{2}$ Department of Cardiology, Congenital Heart Disease and Electrotherapy, \\ Silesian Center for Heart Disease, Medical University of Silesia, Zabrze, Poland
}

\begin{abstract}
Background: The presence of normal thrombolysis in myocardial infarction (TIMI) flow grade 3 before percutaneous coronary intervention (PCI) is associated with better outcomes. The aim of this study was to evaluate the association of spontaneous reperfusion (SR) before PCI and its effect on the immediate and long-term outcomes in diabetic patients.
\end{abstract}

Methods: A total of 1,850 patients with myocardial infarction and multivessel coronary artery disease undergoing primary PCI were enrolled and divided into 4 groups: (1) patients with diabetes mellitus (DM) and initial TIMI < 3 flow $(n=491)$, (2) patients with DM and initial TIMI 3 flow $(n=48)$, (3) patients without DM and with initial TIMI $<3$ flow $(n=1,196)$, (4) patients without DM and with initial TIMI 3 flow $(n=115)$.

Results: SR before PCI was similar in diabetic and non-diabetic patients $(8.9 \%$ vs. $8.8 \%$, $p=0.8)$. DM was not an independent predictor of either pre-procedural or post-procedural TIMI 3 flow. In-hospital mortality rate was the highest in group 1 and the lowest in group 4 $(p<0.0001)$. Death rates of patients from groups 2 and 3 were similar (approximately 8.3\% each, $p=0.9$ ). Non-diabetic patients had a higher 1-year survival rate than diabetic patients, irrespective of their initial TIMI flow.

Conclusions: $S R$ is associated with a similar post-PCI improvement in epicardial blood flow both in diabetic and non-diabetic patients. SR improves in-hospital survival of diabetic patients, which is similar to the survival of non-diabetic patients without SR. The beneficial effect of SR in diabetic patients disappears during 1-year follow-up. (Cardiol J 2013; 20, 4: 378-384)

Key words: diabetes mellitus, spontaneous reperfusion, myocardial infarction

Address for correspondence: Andrzej Lekston, MD, PhD, $3^{\text {rd }}$ Department of Cardiology, Silesian Center for Heart Disease, Medical University of Silesia, ul. Curie-Skłodowskiej 9, 41-800 Zabrze, Poland, tel: +48 3237336 19, fax: +48 322732679 , e-mail: alekston@onet.pl

Received: 17.11.2012 Accepted: 14.12.2012 


\section{Introduction}

Percutaneous coronary intervention (PCI) has revolutionized the management and outcomes of patients with ST-segment elevation myocardial infarction (STEMI) [1]. Primary PCI, according to the European Society of Cardiology (ESC) 2008 guidelines, is the treatment of choice in patients with STEMI within $12 \mathrm{~h}$ of chest pain onset [2]. However, the time delay associated with transportation to a hospital with a catheterization laboratory is a major drawback of primary PCI and may have an adverse effect on outcomes [3]. Diabetes mellitus (DM) is associated with a greater extent of myocardial ischemia and increased mortality after STEMI $[4,5]$. The presence of normal thrombolysis in myocardial infarction (TIMI) flow grade 3 in the infarct-related artery (IRA) before PCI improves left ventricular function, lowers incidence of congestive heart failure, and decreases mortality compared to patients without initial TIMI flow grade $3[6,7]$. Yet, its incidence and impact among diabetic patients are unclear. Patients with DM have impaired endogenous fibrinolytic activity [8]. Therefore, the rate of spontaneous reperfusion (SR) before PCI may be altered and may have an adverse effect on outcomes.

The aim of this study was to evaluate the association of DM with the rate of SR before PCI and its effect on the immediate and long-term outcomes. This is an analysis of patients with STEMI and multivessel coronary artery disease (CAD), who are in our database (unpublished data).

\section{Methods}

A total of 1,850 patients with STEMI and multivessel CAD undergoing primary PCI were enrolled and divided into 4 groups depending on their DM status and initial TIMI flow in the IRA:

- Group 1 - patients with DM and initial TIMI $<3$ flow $(\mathrm{n}=491)$;

- Group 2 - patients with DM and initial TIMI 3 flow $(\mathrm{n}=48)$;

- Group 3 - patients without DM and with initial TIMI $<3$ flow $(\mathrm{n}=1,196)$;

- Group 4 - patients without DM and with initial TIMI 3 flow $(\mathrm{n}=115)$.

SR before PCI was defined as the presence of TIMI 3 flow in the IRA. Multivessel CAD was defined as the presence of at least $70 \%$ stenosis of at least 2 epicardial coronary arteries. DM was defined as: (a) preexisting condition diagnosed before STEMI (patients on insulin, oral glucose-lowering drugs or on a diet), (b) newly diagnosed DM based on fasting plasma glucose $(\mathrm{FPG}) \geq 7.0 \mathrm{mmol} / \mathrm{L}$ or 2-h plasma glucose $\geq 11.1 \mathrm{mmol} / \mathrm{L}$ during an oral glucose tolerance test (OGTT) [9]. To avoid acute hyperglycemia, FPG was taken into consideration after the third day of hospital stay. For that reason, OGTT was performed on day 4 of hospital stay or later. The definition of STEMI was as follows: 1) ST-segment elevation consistent with MI of at least $2 \mathrm{~mm}$ in contiguous precordial leads and/or ST-segment elevation of at least $1 \mathrm{~mm}$ in 2 or more limb leads or new left bundle branch block, and 2) positive cardiac necrosis markers (CK-MB and/or troponin). Patients received $300 \mathrm{mg}$ of acetylsalicylic acid (ASA) loading dose and $600 \mathrm{mg}$ of clopidogrel loading dose, followed by $75 \mathrm{mg}$ of ASA maintenance dose and $75 \mathrm{mg}$ of clopidogrel maintenance dose [10]. Coronary angiography and PCI were performed using standard protocols and guidelines. A culprit lesion was described in the presence of an acute occlusion, intraluminal filling defects (or thrombus), ulcerated plaques, dissection, or intraluminal flaps. The baseline and post-procedural blood flow in the IRA was quantified with the TIMI grading system [11]. Angiographic measurements were made using quantitative coronary angiography and the automated coronary analysis system (CDM 3500 View Station, Philips Medical Systems, Leiden, The Netherlands). All patients received bare-metal stents. Successful PCI was defined as a post-procedural residual-diameter stenosis $<30 \%$, with TIMI 3 flow in the IRA and no procedural complications.

All patients were scheduled for an elective 1-year clinical follow-up. We clinically monitored the patients for cardiovascular events. The major adverse cardiac and cerebrovascular events included death, rehospitalization for acute coronary syndromes (STEMI, non-STEMI, unstable angina), and stroke.

Approval for analyzing recorded data was waived by the local bioethics committee on human research given the retrospective nature of the study.

\section{Statistical analysis}

Quantitative data are presented as means \pm \pm standard deviations (SD) or medians with interquartile ranges (lower and upper quartiles). Qualitative data are presented as frequencies. The Shapiro-Wilk test was used to determine whether random samples came from a normal distribution. The $\chi^{2}$ test with Yates' correction was used to compare categorical variables. The Kruskal-Wallis analysis of variance (ANOVA) test was used to compare continuous variables between groups. One-year survival was estimated with the Kaplan- 
Table 1. Patients' baseline and clinical characteristics.

\begin{tabular}{|c|c|c|c|c|c|}
\hline & $\begin{array}{l}\text { Group } 1 \\
(\mathrm{n}=491)\end{array}$ & $\begin{array}{l}\text { Group } 2 \\
(\mathrm{n}=48)\end{array}$ & $\begin{array}{c}\text { Group } 3 \\
(n=1196)\end{array}$ & $\begin{array}{l}\text { Group } 4 \\
(\mathrm{n}=115)\end{array}$ & $\mathbf{P}$ \\
\hline Age [years] & $64.3 \pm 9.6$ & $63.9 \pm 8.1$ & $59.9 \pm 10.5$ & $57.7 \pm 10.9$ & $<0.0001$ \\
\hline Females & $214(43.5 \%)$ & $18(35.9 \%)$ & $276(23.1 \%)$ & $23(20.0 \%)$ & $<0.0001$ \\
\hline Systemic hypertension & $363(73.9 \%)$ & $36(62.5 \%)$ & $624(52.2 \%)$ & $62(53.9 \%)$ & $<0.0001$ \\
\hline Prior myocardial infarction & $191(30.7 \%)$ & $16(33.3 \%)$ & $315(26.3 \%)$ & $33(28.7 \%)$ & 0.18 \\
\hline Hospital stay [days] & $9.5 \pm 6.0$ & $9.7 \pm 5.1$ & $8.9 \pm 5.1$ & $9.2 \pm 4.1$ & 0.15 \\
\hline $\begin{array}{l}\text { Time from symptom onset [h], } \\
\text { median (interquartile range) }\end{array}$ & $6.0(4.0-9.0)$ & $5.0(3.5-6.5)$ & $5.0(3.0-7.0)$ & $4.0(2.0-5.5)$ & $<0.0001$ \\
\hline $\begin{array}{l}\text { LVEF }[\%], \text { median } \\
\text { (interquartile range) }\end{array}$ & $42(35-48)$ & $40(35-50)$ & $45(40-50)$ & $45(39-50)$ & 0.0001 \\
\hline Body mass index & $26.8 \pm 1.3$ & $27.1 \pm 1.5$ & $25.4 \pm 1.6$ & $24.9 \pm 2.1$ & 0.15 \\
\hline Aspirin & $482(98.1 \%)$ & $48(100 \%)$ & $1183(98.9 \%)$ & $114(99.1 \%)$ & 0.9 \\
\hline $\begin{array}{l}\text { Thienopyridines } \\
\text { (clopidogrel/ticlopidine) }\end{array}$ & $452(92.1 \%)$ & $44(91.7 \%)$ & $1112(91.9 \%)$ & $105(91.3 \%)$ & 0.7 \\
\hline Bea-blockers & $412(83.9 \%)$ & $39(81.2 \%)$ & $981(82.0 \%)$ & $93(80.8 \%)$ & 0.6 \\
\hline ACE inhibitors & $383(78.0 \%)$ & $36(75.0 \%)$ & $740(61.9 \%)$ & $73(63.4 \%)$ & 0.01 \\
\hline Statins & $402(81.9 \%)$ & $39(81.2 \%)$ & $937(78.3 \%)$ & $92(80.0 \%)$ & 0.5 \\
\hline In-hospital death & $68(13.8 \%)$ & $4(8.3 \%)^{*}$ & $99(8.3 \%)^{*}$ & $1(0.9 \%)$ & $<0.0001$ \\
\hline
\end{tabular}

${ }^{*} p=0.99 ;$ LVEF — left ventricular ejection fraction; ACE — angiotensin converting enzyme

Table 2. Angiographic findings.

\begin{tabular}{|c|c|c|c|c|c|}
\hline & $\begin{array}{c}\text { Group } 1 \\
(\mathrm{n}=491)\end{array}$ & $\begin{array}{l}\text { Group } 2 \\
(n=48)\end{array}$ & $\begin{array}{c}\text { Group } 3 \\
(n=1196)\end{array}$ & $\begin{array}{l}\text { Group } 4 \\
(n=115)\end{array}$ & $\mathbf{P}$ \\
\hline Infarct-related artery: & & & & & 0.8 \\
\hline LAD & $209(42.5 \%)$ & $20(41.7 \%)$ & $504(42.1 \%)$ & $48(41.7 \%)$ & \\
\hline $\mathrm{Cx}$ & $98(20.0 \%)$ & $9(18.7 \%)$ & $245(20.5 \%)$ & $24(20.9 \%)$ & \\
\hline $\mathrm{RCA}$ & $172(35.0 \%)$ & $18(37.5 \%)$ & $406(33.9 \%)$ & $41(35.46 \%)$ & \\
\hline Other & $12(2.5 \%)$ & $1(2.1 \%)$ & $41(3.4 \%)$ & $2(1.7 \%)$ & \\
\hline 2-vessel CAD & $275(56.0 \%)$ & $28(58.3 \%)$ & $650(54.3 \%)$ & $63(54.7 \%)$ & 0.8 \\
\hline 3-vessel CAD & $216(44.0 \%)$ & $20(41.7 \%)$ & $541(45.2 \%)$ & $52(45.3 \%)$ & 0.8 \\
\hline Final TIMI 3 flow & $407(82.9 \%)^{*}$ & $46(97.9 \%)^{\dagger}$ & $1033(86.4 \%)^{*}$ & $114(99.1 \%)^{\dagger}$ & $<0.0001$ \\
\hline
\end{tabular}

${ }^{*} p=0.5$ (group 1 vs. group 3); ${ }^{\dagger} p=0.8$ (group 2 vs. group 4); CAD - coronary artery disease; LAD — left anterior descending branch; $\mathrm{Cx}$ - circumflex artery; RCA — right coronary artery; TIMI — thrombolysis in myocardial infarction

-Meier method and compared with the log-rank test. All clinical variables and laboratory findings with a $\mathrm{p}$ value $\leq 0.2$ in the univariate analysis were entered into the multivariate logistic regression model using a Wald statistic backward stepwise selection. Multivariate logistic regression analysis was performed to estimate odds ratios (OR) and $95 \%$ confidence intervals $(95 \% \mathrm{CI})$ to identify independent predictors of baseline and final TIMI 3 flow. The Cox proportional hazard survival model was used to assess the association between TIMI flow grade and 1-year mortality while adjusting for potential confounders. A value of $p<0.05$ was considered significant.

\section{Results}

A total of 539 diabetic patients entered the study, of whom 48 (8.9\%) had SR before PCI. Additionally, 1,311 non-diabetic patients were enrolled, of whom 115 (8.8\%) had SR before PCI ( $\mathrm{p}=0.8)$. Baseline and clinical characteristics are presented in Table 1. Diabetic patients (irrespective of initial TIMI flow) were older and more frequently female. The time from symptoms onset was substantially longer in diabetic patients with no SR before PCI. The duration of chest pain was similar in the other 3 groups. Angiographic parameters were similar (Table 2) except for the rate of final TIMI 3 flow, 
Table 3. Laboratory findings.

\begin{tabular}{lccccc}
\hline & $\begin{array}{c}\text { Group 1 } \\
(\mathbf{n}=\mathbf{4 9 1 )}\end{array}$ & $\begin{array}{c}\text { Group 2 } \\
(\mathbf{n}=\mathbf{4 8})\end{array}$ & $\begin{array}{c}\text { Group 3 } \\
(\mathbf{n}=\mathbf{1 1 9 6 )}\end{array}$ & $\begin{array}{c}\text { Group 4 } \\
\text { (n = 115) }\end{array}$ & P \\
\hline Leucocytes $\left[10^{3} / \mathrm{mm}^{3}\right]$ & $14.0 \pm 5.5$ & $14.9 \pm 5.1$ & $13.8 \pm 6.0$ & $13.8 \pm 6.5$ & 0.8 \\
Erythrocytes $\left[10^{6} / \mathrm{mm}^{3}\right]$ & $4.5 \pm 0.6$ & $4.6 \pm 0.6$ & $4.6 \pm 0.6$ & $4.8 \pm 0.7$ & 0.3 \\
Hemoglobin $[\mathrm{mmol} / \mathrm{L}]$ & $8.7 \pm 0.9$ & $9.0 \pm 0.9$ & $9.2 \pm 1.0$ & $9.0 \pm 0.7$ & 0.7 \\
Hematocrit $[\%]$ & $41 \pm 5$ & $43 \pm 5$ & $43 \pm 4$ & $44 \pm 5$ & 0.5 \\
Platelets $\left[10^{3} / \mathrm{mm}^{3}\right]$ & $218 \pm 68$ & $241 \pm 73$ & $232 \pm 72$ & $224 \pm 68$ & 0.2 \\
Admission glucose $[\mathrm{mmol} / \mathrm{L}]$ & $9.0 \pm 4.0$ & $9.0 \pm 3.2$ & $8.6 \pm 3.9$ & $8.6 \pm 4.0$ & 0.3 \\
Total cholesterol $[\mathrm{mmol} / \mathrm{L}]$ & $5.9(5.0-7.1)$ & $5.8(5.3-6.9)$ & $6.2(5.5-7.5)$ & $6.0(5.0-7.8)$ & 0.8 \\
HDL cholesterol $[\mathrm{mmol} / \mathrm{L}]$ & $1.3(1.1-1.7)$ & $1.5(1.3-1.8)$ & $1.5(1.3-2.0)$ & $1.6(1.4-2.1)$ & 0.7 \\
LDL cholesterol $[\mathrm{mmol} / \mathrm{L}]$ & $4.1(3.1-4.6)$ & $3.8(3.2-4.2)$ & $3.7(2.8-4.7)$ & $3.8(3.1-4.6)$ & 0.6 \\
Triglycerides $[\mathrm{mmol} / \mathrm{L}]$ & $1.5(0.8-2.4)$ & $1.4(0.9-2.3)$ & $1.3(1.0-2.2)$ & $1.4(0.7-2.1)$ & 0.7 \\
Serum creatinine $[\mu \mathrm{mol} / \mathrm{L}]$ & $95(75-114)$ & $92(73-109)$ & $91(74-105)$ & $87(63-104)$ & 0.4 \\
Peak CPK $[\mathrm{IU} / \mathrm{L}]$ & $2321(1251-2747)$ & $1730(956-2144)$ & $2179(947-2633)$ & $1698(899-2038)$ & 0.03
\end{tabular}

CPK — creatine phosphokinase

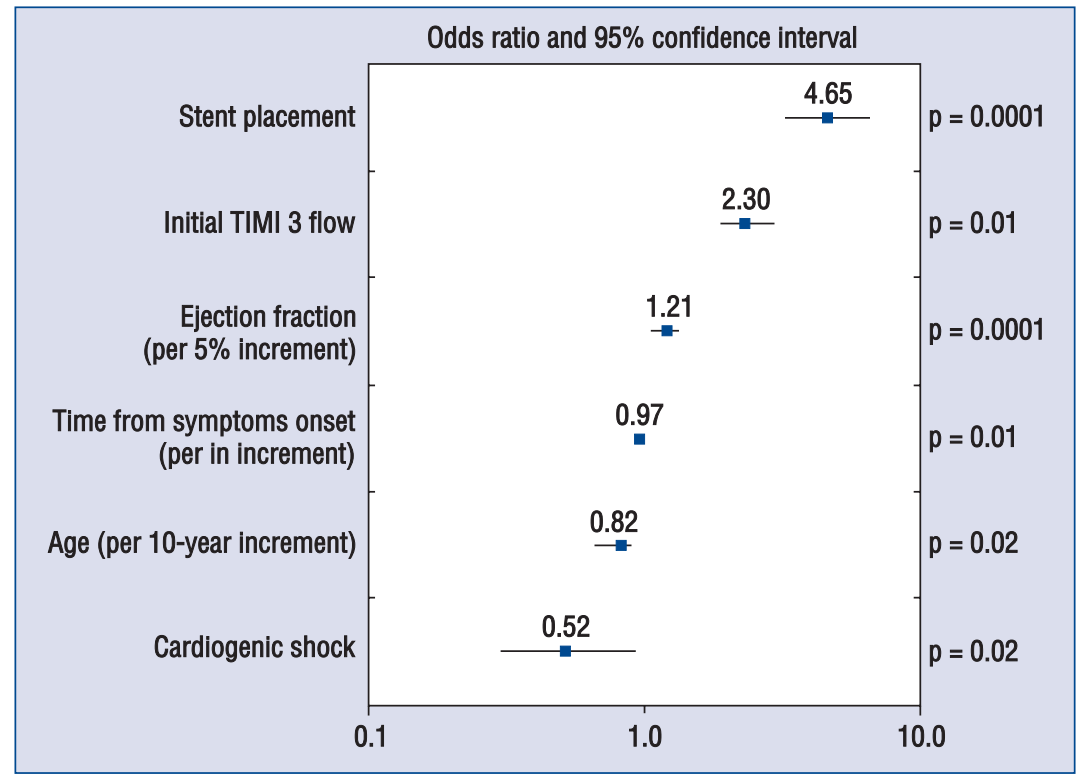

Figure 1. Independent predictors of achieving final TIMI 3 flow.

which was higher in patients with SR (irrespective of their diabetes status). Laboratory findings are given in Table 3. Peak creatine phosphokinase was higher in diabetic and non-diabetic patients with initial TIMI $0-2$ flow (group 1 and group $3)$. In-hospital mortality rate was the highest in group 1 and the lowest in group $4(\mathrm{p}<0.0001)$. Meanwhile, the death rates of patients from groups 2 and 3 were similar (approximately 8.3\% each, $\mathrm{p}=0.9$ ). Multivariate logistic regression revealed that only cardiogenic shock on admission (OR $0.25,95 \%$ CI $0.10-0.63, \mathrm{p}=0.003)$ and time from symptoms onset (OR $0.95,95 \%$ CI $0.90-0.99, \mathrm{p}=0.03$ ) independently decreased the chance of SR before PCI. Independent predictors of final TIMI 3 flow are depicted in Figure 1. Cardiogenic shock, DM, older age, time from symptoms onset, ejection fraction, and final TIMI 3 flow independently predicted in-hospital mortality (Fig. 2). Non-diabetic patients had a higher 1-year survival rate than diabetic patients, irrespective of their initial TIMI flow (Fig. 3). The Cox proportional hazard survival model showed that only DM, cardiogenic shock, and older age were independently associated with 1-year mortality, whereas higher ejection fraction and 


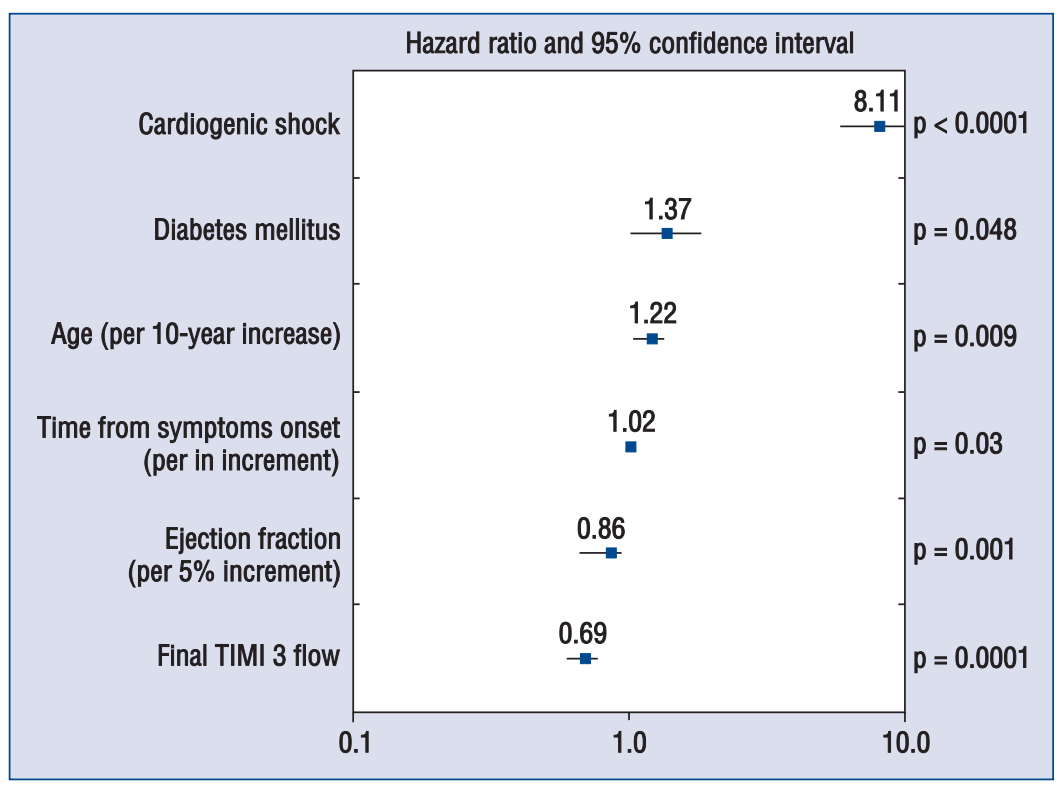

Figure 2. Independent predictors of in-hospital death.

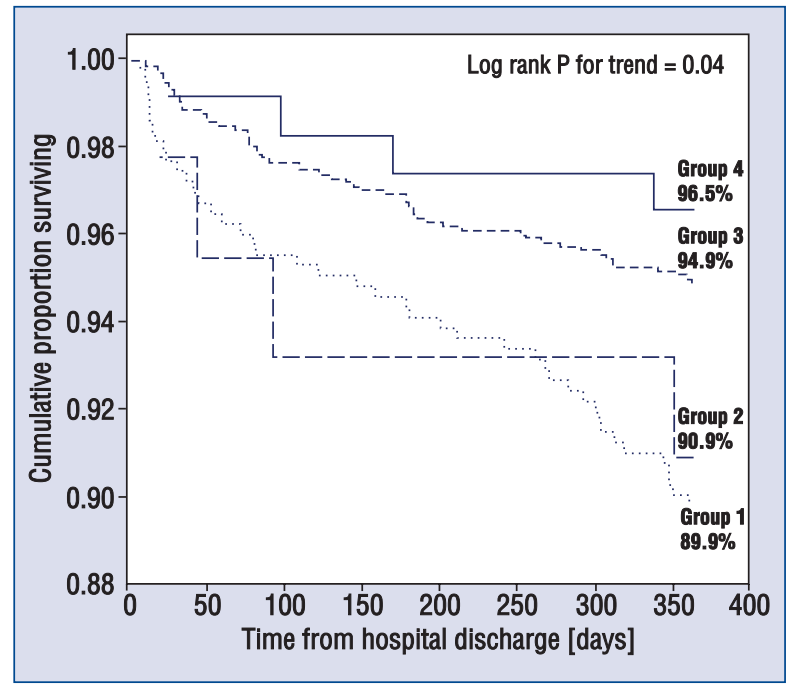

Figure 3. Kaplan-Meier curves for 1-year survival.

final TIMI 3 flow decreased the risk of death in long-term follow-up (Fig. 4).

\section{Discussion}

The results of our study indicate that the rate of SR before PCI was similar in diabetic and non-diabetic patients ( $8.9 \%$ vs. $8.8 \%)$. Of note, diabetic patients with no SR had substantially longer time from symptoms onset than diabetic patients with SR and all non-diabetic patients. Multivariate logistic regression revealed that only cardiogenic shock and the time from symptoms onset were independent predictors of SR before PCI. The presence of initial TIMI 3 flow was associated with successful PCI both in diabetic and non-diabetic patients. Our study documents superior outcomes in patients who achieve TIMI 3 flow before intervention. In-hospital mortality was the highest in diabetic patients with no SR, intermediate in diabetic patients with SR and non-diabetic patients with no SR, and the lowest in non-diabetic patients with SR. Non-diabetic patients, irrespective of their reperfusion on admission status, had a good 1-year survival rate. Diabetic patients (irrespective of their reperfusion on admission status) had a worse survival rate than non-diabetics. Post-procedural success (final TIMI 3 flow) but not SR (initial TIMI 3 flow) was an independent predictor of 1-year mortality.

Diabetic and non-diabetic patients with initial TIMI 3 flow also had higher procedural success and smaller infarct sizes (lower peak creatine kinase values). Despite smaller infarct size and lower procedural success, a greater preservation of left ventricular function was observed only in non-diabetic patients.

Unfavorable course of STEMI in diabetic patients may be associated with endothelial dysfunction, promoting vasoconstriction; inflammation and hypercoagulability [12-14]; increased platelet aggregation, leading to thrombosis $[15,16]$; and impaired endogenous fibrinolytic activity [8, 17]. The rate of SR in our study was similar to that observed in other studies [18-20]. Unlike other studies, 


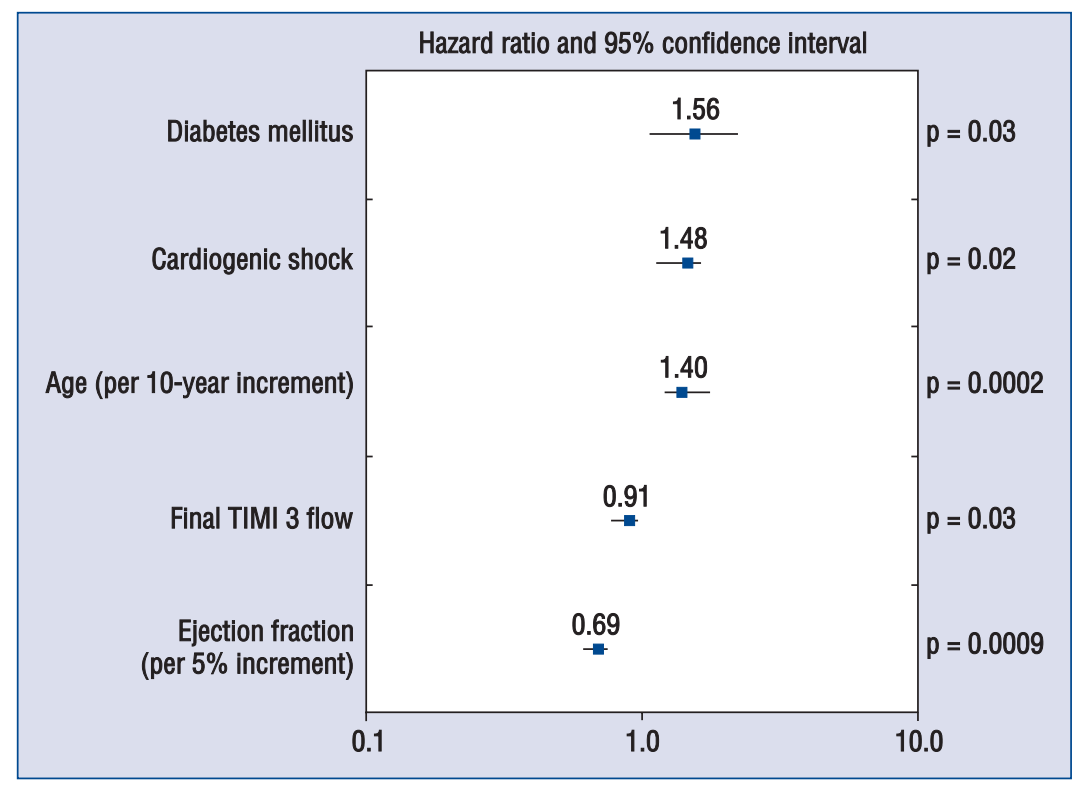

Figure 4. Independent predictors of 1-year mortality.

our reports similar frequencies of SR in diabetic and non-diabetic patients. The benefit of SR before intervention is due to multiple factors and has been studied in a few reports. Gustafson et al. [21] reported that patients with initial TIMI 2 or 3 flow had lower mortality $(1.7 \%$ vs. $4.3 \%, \mathrm{p}=0.02)$ and a higher acute ejection fraction $(49.5 \%$ vs. $47.1 \%, \mathrm{p}=0.002)$. Brodie et al. [22] presented similar results. Interestingly, they both observed a better ejection fraction in patients with patent IRA on initial angiography. In our study, we observed no association between initial TIMI flow and ejection fraction. However, we did observe that diabetic patients (irrespective of their SR status) had more depressed left ventricular contractile function. Stone et al. [6], in an analysis of 2,507 patients from four major PAMI trials, found that initial TIMI 3 flow was a powerful and independent predictor of in-hospital and late survival. We observed a similar trend in our study; nevertheless, SR on admission was not independently correlated with in-hospital and late survival. Only final TIMI 3 flow was an independent predictor of better survival. Supporting the role of pre-procedural IRA patency, De Luca et al. [24] found initial TIMI flow to be independently associated with 1-year mortality in high-risk patients (according to TIMI risk score [23]), but not in low-risk patients.

There is only 1 prior report on the association of initial TIMI flow and DM. Bainey et al. [25] analyzed 4,944 patients (15.5\% diabetic) undergoing primary PCI in the APEX AMI study. They reported that patients with SR had improved post-PCI
TIMI 3 flow compared to those without SR in non-diabetic patients (99.8\% vs. $90.3 \%, \mathrm{p}<0.001)$ and in diabetic patients $(98.6 \%$ vs. $84.9 \%, \mathrm{p}<0.001)$. They also observed that non-diabetic patients with SR showed a significant improvement in 90-day death/shock/congestive heart failure compared with those without SR: $4.4 \%$ vs. $8.9 \%(p=0.001)$. However, the composite outcome in diabetic patients did not reach statistical significance: $-10.0 \%$ with SR vs. $14.9 \%$ without $(\mathrm{p}=0.270)$. Although they observed a trend towards improved 90-day mortality in non-diabetic patients with or without SR $(2.2 \%$ vs. $3.6 \%, \mathrm{p}=0.1)$, no mortality benefit was evident in diabetic patients with or without SR $(4.3 \%$ vs. $6.1 \%, \mathrm{p}=0.79)$. Notably, when they examined outcomes according to tertiles of baseline blood glucose, both non-diabetic and diabetic patients with normoglycemia showed higher SR rates $(15.5 \%, 10.3 \%$, and $7.3 \%$ for non-diabetic patients, $\mathrm{p}<0.001 ; 17.4 \%, 7.2 \%$, and $9.1 \%$ for diabetic patients, $\mathrm{p}=0.132$ ) and improved 90 -day death/shock/congestive heart failure $(5.2 \%, 8.3 \%$, and $14 \%$ for non-diabetic patients, $\mathrm{p}<0.001 ; 8.7 \%$, $4.2 \%$, and $15.8 \%$ for diabetic patients, $\mathrm{p}=0.006$ ).

\section{Limitations of the study}

Our study has several limitations. TIMI flow in the IRA was assessed visually by the operator rather than by core laboratory analysis. We did not perform an analysis on the association between baseline glucose levels and the rate of SR. Because we analyzed patients with multivessel CAD, we do 
not know whether revascularization procedures during follow-up were elective (staged revascularization) or repeat revascularizations; therefore, we intentionally omitted this information in the results. Finally, these are observational data from one institution.

\section{Conclusions}

Diabetes mellitus is not an independent predictor of either pre-procedural or post-procedural TIMI 3 flow. When SR before intervention occurs, it is associated with a similar post-PCI improvement in epicardial blood flow both in diabetic and non-diabetic patients. SR improves in-hospital survival of diabetic patients, which is similar to the survival of non-diabetic patients without SR. The beneficial effect of SR in diabetic patients disappears during 1-year follow-up.

All authors have contributed substantially to the study, drafted the article, revised it and gave final approval of the version to be published.

\section{Conflict of interest: none declared}

\section{References}

1. A clinical trial comparing primary coronary angioplasty with tissue plasminogen activator for acute myocardial infarction. The Global Use of Strategies to Open Occluded Coronary Arteries in Acute Coronary Syndromes (GUSTO IIb) Angioplasty Substudy Investigators. N Engl J Med, 1997; 336: 1621-1628.

2. Van de Werf F, Bax J, Betriu A et al.; ESC Committee for Practice Guidelines (CPG), Management of acute myocardial infarction in patients presenting with persistent ST-segment elevation: the Task Force on the Management of ST-Segment Elevation Acute Myocardial Infarction of the European Society of Cardiology. Eur Heart J, 2008; 29: 2909-2945.

3. Mak KH, Moliterno DJ, Granger CB et al. Influence of diabetes mellitus on clinical outcome in the thrombolytic era of acute myocardial infarction. GUSTO-I Investigators. Global Utilization of Streptokinase and Tissue Plasminogen Activator for Occluded Coronary Arteries. J Am Coll Cardiol, 1997; 30: 171-179.

4. Haffner FM, Lehto S, Ronnemaa T et al. Mortality from coronary heart disease in subjects with type 2 diabetes and in nondiabetic subjects with and without prior myocardial infarction. N Engl J Med, 1998; 339: 229-234.

5. Berger PB, Ellis SG, Holmes DR Jr, et al. Relationship between delay in performing direct coronary angioplasty and early clinical outcome in patients with acute myocardial infarction: results from the global use of strategies to open occluded arteries in Acute Coronary Syndromes (GUSTO-IIb) trial. Circulation, 1999; 100: 14-20.

6. Stone GW, Cox D, Garcia E et al. Normal flow (TIMI-3) before mechanical reperfusion therapy is an independent determinant of survival in acute myocardial infarction: analysis from the primary angioplasty in myocardial infarction trials Circulation, 2001; 6: 636-641.

7. Cannon CP. Importance of TIMI 3 flow. Circulation, 2001; 104: 624-626.
8. Erem C, Hacihasanoğlu A, Celik S et al. Coagulation and fibrinolysis parameters in type 2 diabetic patients with and without diabetic vascular complications. Med Princ Pract, 2005; 14: $22-30$.

9. Rydén L, Standl E, Bartnik M et al. Task Force on Diabetes and Cardiovascular Diseases of the European Society of Cardiology (ESC); European Association for the Study of Diabetes (EASD). Guidelines on diabetes, pre-diabetes, and cardiovascular diseases: executive summary. The Task Force on Diabetes and Cardiovascular Diseases of the European Society of Cardiology (ESC) and of the European Association for the Study of Diabetes (EASD). Eur Heart J, 2007; 28: 88-136.

10. Silber S, Albertsson P, Avilés FF et al. Task Force for Percutaneous Coronary Interventions of the European Society of Cardiology. Guidelines for percutaneous coronary interventions. The Task Force for Percutaneous Coronary Interventions of the European Society of Cardiology. Eur Heart J, 2005; 26: 804-847.

11. TIMI Study Group Definitions used in TIMI trials: http://www. timi.org. Accessed January 22, 2008.

12. Calles-Escandon J, Cipolla M. Diabetes and endothelial dysfunction: a clinical perspective. Endocr Rev, 2001; 22: 787-790.

13. Hsueh WA, Lyon CJ, Quiñones MJ. Insulin resistance and the endothelium. Am J Med, 2004; 117: 109-117.

14. Aronson D, Rayfield EJ, Chesebro JH. Mechanisms determining course and outcome of diabetic patients who have had acute myocardial infarction. Ann Intern Med, 1997; 126: 296-306.

15. Winocour PD. Platelet abnormalities in diabetes mellitus. Diabetes, 1992; 41 (suppl. 2): 26-31.

16. Davì G, Catalano I, Averna $\mathrm{M}$ et al. Thromboxane biosynthesis and platelet function in type II diabetes mellitus. N Engl J Med, 1990; 322: 1769-1774.

17. Nordt TK, Bode C. Impaired endogenous fibrinolysis in diabetes mellitus: mechanisms and therapeutic approaches. Semin Thromb Hemost, 2000; 26: 495-501.

18. Cannon CP, Gibson CM, Lambrew CT et al. Relationship of symptom onset-to-balloon time and door-to-balloon time with mortality in patients undergoing angioplasty for acute myocardial infarction. JAMA, 2000; 283: 2941-2947.

19. Grines CL, Browne KF, Marco J et al. A comparison of immediate angioplasty with thrombolytic therapy for acute myocardial infarction. N Engl J Med, 1993; 328: 673-679.

20. Stone GW, Grines CL, Browne KF et al. Predictors of in-hospital and 6 month outcome after acute myocardial infarction in the reperfusion era: the Primary Angioplasty in Myocardial Infarction (PAMI) trial. J Am Coll Cardiol, 1995; 25: 370-377.

21. Gustafson JG, Cox D, Garcia E et al. Spontaneous patency in the early hours of AMI: incidence, predictors and prognostic implications (abstract). Circulation, 1998; 98 (suppl. I): I1-I22.

22. Brodie BR, Stuckey TD, Hansen C et al. Benefit of coronary reperfusion before intervention on outcomes after primary angioplasty for acute myocardial infarction. Am J Cardiol, 2000; 85: $13-18$.

23. Morrow DA, Antman EM, Charlesworth A et al. TIMI risk score for ST-elevation myocardial infarction: a convenient, bedside, clinical score for risk assessment at presentation - an intravenous nPA for treatment of infarcting myocardium early II trial substudy. Circulation, 2000;102: 2031-2037.

24. De Luca G, Ernst N, Zijlstra F, van't Hof AW et al. Preprocedural TIMI flow and mortality in patients with acute myocardial infarction treated by primary angioplasty. J Am Coll Cardiol, 2004; 43: 1363-1367.

25. Bainey KR, Fu Y, Granger CB et al. APEX AMI Investigators. Benefit of angiographic spontaneous reperfusion in STEMI: does it extend to diabetic patients? Heart, 2009; 95: 1331-1336 . 